\title{
Nighttime Cool Skin Effect Observed from Infrared SST Autonomous Radiometer (ISAR) and Depth Temperatures
}

\author{
HAIFENG ZHANG \\ Department of Infrastructure Engineering, University of Melbourne, Melbourne, Victoria, Australia \\ HELEN BEGGS \\ Bureau of Meteorology, Melbourne, Victoria, Australia \\ AlexANDER IGNATOV \\ NOAA/STAR, College Park, Maryland
}

AlEXANDER V. BABANIN

Department of Infrastructure Engineering, University of Melbourne, Melbourne, Victoria, Australia, and Laboratory for Regional Oceanography and Numerical Modeling, National Laboratory for Marine Science and Technology, Qingdao, China

(Manuscript received 20 September 2019, in final form 24 October 2019)

\begin{abstract}
The nighttime ocean cool skin signal $\Delta T$ [defined as skin sea surface temperature ( $\mathrm{SST}_{\text {skin }}$ ) minus depth SST $\left.\left(\mathrm{SST}_{\text {depth }}\right)\right]$ is investigated using 103 days of matchups between shipborne Infrared SST Autonomous

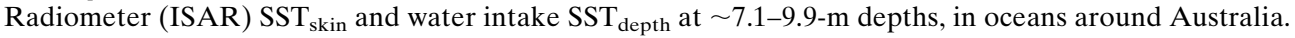

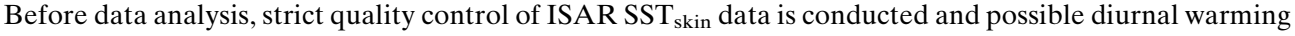
contamination is carefully minimized. The statistical distribution of $\Delta T$, and its dependencies on wind speed, heat flux, etc., are consistent with previous findings. The overall average $\Delta T$ value is $-0.23 \mathrm{~K}$. It is observed that the magnitude of the cool skin signal increases after midnight and a coolest skin offset (with an average value of $-0.36 \mathrm{~K}$ ) is found at around dawn. The dependency of $\Delta T$ on SST conditions is observed. Direct warm skin events are discovered when the net heat flux direction is from the atmosphere to the ocean, which is more likely to occur at high latitudes when the air is very humid and warmer than the SST. In addition, several cool skin models are validated: one widely used physical model performs best and can capture most skin-effect trends and details; the empirical models only reflect the basic features of the observed $\Delta T$ values. If the user cannot apply the physical model (due to, e.g., the algorithm complexity or missing inputs), then the empirical parameterization in the form proposed in a 2002 study can be used. However, we recommend using a new set of parameters, calculated in this study, based on much more representative dataset, and with more rigorous quality control.
\end{abstract}

\section{Introduction}

Under most conditions, the skin sea surface temperature [ $\mathrm{SST}_{\text {skin }}$; measured at $10-20-\mu \mathrm{m}$ depth by an infrared (IR) sensor operated at 3.7-12- $\mu \mathrm{m}$ wavelengths] is slightly cooler, typically by a few tenths of a degree, than the water temperature below the surface [SST ${ }_{\text {subskin }}$; measured at $\sim 1$-mm depth by a microwave (MW) sensor]. This is referred to as the cool skin effect or "skin effect," for short (e.g., Woodcock 1941; Saunders 1967). This temperature

Corresponding author: Haifeng Zhang, haifeng.zhang@ymail.com difference is due to the net heat flux through the thermal boundary layer in the top millimeter, which is usually from the ocean to the atmosphere. Hence, the cool skin effect exists nearly all the time. However, in the daytime when the wind is calm and solar insolation strong, the cool skin effect may be offset by diurnal warming (DW) in the upper few meters, which is defined as the temporary temperature increase due to daytime solar heating and can sometimes have amplitudes of several kelvins (e.g., Fairall et al. 1996a, hereafter F96; Gentemann et al. 2003).

Proper understanding of the cool skin effect is important as it has direct relevance to both air-sea interactions and 
remote sensing of satellite IR $\mathrm{SST}_{\text {skin }}$ retrievals (Castro et al. 2003). For instance, correctly accounting for the skin effect, together with DW within the top few meters, can enhance the performance of a numerical weather prediction (NWP) or climate model, as air-sea interactions can be more accurately estimated using temperatures closer to the actual interface (e.g., Robertson and Watson 1992; Zeng and Beljaars 2005; Masson et al. 2012; Clayson and Bogdanoff 2013; Akella et al. 2017). In addition, the validation of satellite IR SST skin $_{\text {data against in situ mea- }}$ surements also requires the skin effect to be appropriately resolved, since in situ $\mathrm{SST}_{\text {depth }}$ (normally measured by a drifting buoy or a mooring at $\sim 20-\mathrm{cm}$ and $\sim 1-\mathrm{m}$ depth, respectively) supposedly represents $\mathrm{SST}_{\text {subskin }}$ under wellmixed conditions [wind speed $>2(6) \mathrm{m} \mathrm{s}^{-1}$ in the night (day); Donlon et al. 2002, hereafter D02].

Therefore, numerous studies have been carried out to quantify and/or model the skin effect (e.g., Saunders 1967; Hasse 1971; Brutsaert 1975; Liu et al. 1979; Hepplewhite 1989; Schluessel et al. 1990; Soloviev and Schlüssel 1994, 1996; F96; Wick et al. 1996; Wick and Jessup 1998; Donlon et al. 1999; Murray et al. 2000; D02; Castro et al. 2003; Minnett 2003; Tu and Tsuang 2005; Wick et al. 2005; Ward 2006; Minnett et al. 2011, hereafter M11; Alappattu et al. 2017, hereafter A17; Zhang et al. 2019). Although some of these studies used satellite $\mathrm{SST}_{\text {skin }}$ data such as Along Track Scanning Radiometers (ATSR) series sensors (e.g., Murray et al. 2000; Horrocks et al. 2003; Zhang et al. 2019), most adopted shipborne skin and depth SST pairs, which are of higher accuracy but sometimes limited in number. A series of physical cool skin models have been developed that can generally be divided into two groups. The first group, represented by the model proposed in Saunders (1967), considers two essential mechanisms controlling the heat fluxes across the molecular skin layer: free convection caused by the thermal instability and the salinity gradient across the cool skin itself under very calm winds $\left(<2 \mathrm{~m} \mathrm{~s}^{-1}\right)$, and forced convection driven by the surface shear stress. Many studies followed Saunders (1967) with foci on determining the Saunders proportionality constant $\lambda$ and then the thickness of the cool skin layer (e.g., Paulson and Simpson 1981; Wu 1985; F96; Artale et al. 2002; Tu and Tsuang 2005). The other group of parameterizations was developed based on the surface renewal theory, which assumes that a part of the surface layer is removed and replaced by water from beneath (e.g., Brutsaert 1975; Liu et al. 1979; Schluessel et al. 1990; Soloviev and Schlüssel 1994; Wick et al. 1996; Castro et al. 2003). In addition to the physical models, empirical parameterizations have also been proposed in more recent studies, relating the skin-effect amplitude to environmental variables such as wind speed (e.g., D02; M11; A17). Different models have been validated and intercompared with each other in several studies (e.g., Kent et al. 1996; Castro et al. 2003; Horrocks et al. 2003; Tu and Tsuang 2005).

Although we now have a reasonably comprehensive understanding of the cool skin effect, some aspects are still not well documented, such as how much solar insolation is absorbed in the skin layer, how the skin effect changes diurnally or even hourly, have warm skin events been observed in the open ocean, and how solid is the assumption of a well-mixed subskin layer, that is, $1 \mathrm{~mm}$ $10 \mathrm{~m}$, under $>2$ (6) $\mathrm{m} \mathrm{s}^{-1}$ conditions in the nighttime (daytime). Some of these gaps are simply due to lack of a dataset that is large enough for statistically significant analyses. For example, M11 reported that there may be a dependence of skin-effect amplitudes on temperatures, yet it is challenging to reach a more robust conclusion due to the small dataset size $(N=311)$. Furthermore, an independent, thorough evaluation of the most widely used cool skin model (F96) also seems so far absent.

In this study, we take advantage of the Infrared SST Autonomous Radiometer (ISAR) skin SSTs and the concurrent depth temperatures and other environmental condition measurements obtained from Australia's Marine National Facility, R/V Investigator, from January 2016 to February 2018. The amount of data is larger than most previous studies. Along with the data analyses is the validation of the several cool skin models. The structure of the paper is as follows: section 2 will introduce the datasets, methods, and models involved; section 3 illustrates the quality control (QC) of the observations and the minimization of DW signals; results are presented in section 4; and section 5 provides the discussion and conclusions.

\section{Data, methods, and models}

\section{a. SST data}

Skin SST data used in this study are measured by an ISAR model 5D onboard Australia's Marine National Facility, R/V Investigator [Beggs et al. 2017; http:// imos.org.au/facilities/shipsofopportunity/sstsensors/; Integrated Marine Observing System (IMOS); IMOS 2018]. The ISAR is a self-calibrating instrument, containing a single channel radiometer $(9.6-11.5 \mu \mathrm{m}$, spectral bandpass), two blackbody reference cavities and a rotating gold mirror, that can measure in situ ocean temperatures at the same depth $(\sim 10 \mu \mathrm{m})$ as IR radiometers on satellites to an accuracy of $\sim 0.1-\mathrm{K}$ root-mean-square error (Donlon et al. 2008; Wimmer and Robinson 2016). ISAR data used in this study have been processed following ISAR calibration using a second-generation Concerted Action for the Study of the Ocean Thermal Skin (CASOTS-II) reference blackbody (Donlon et al. 2014) before and after each cruise over the expected SST range for that cruise (N. Morgan 2019, personal 
communication). Uncertainty code produced by Werenfrid Wimmer, based on Wimmer and Robinson (2016), is used to calculate the total expanded uncertainty for the skin SST value, with version 3.1 code used for 2016-17 data and version 3.8 for 2018 data. The total expanded uncertainty estimate is a combination of random (type A), systematic (type B), instrument, and measurement uncertainty (including the uncertainty of the CASOTS-II blackbody, set at $0.05 \mathrm{~K}$ ), and varies with the roll of the ship and the internal ISAR temperature. The ISAR total uncertainty is an estimate of the SST that differs from its true value by less than the stated uncertainty in $95 \%$ of cases, and can be considered as about 2 times the standard deviation (SD). In this study, only values with total uncertainty $\leq 0.2 \mathrm{~K}$ are adopted (see section 3 for more detail). The temporal resolution of the ISAR data is $\sim 2.5 \mathrm{~min}$ and is reported to the closest minute in the IMOS R/V Investigator "ISAR_QC" files (IMOS 2018). The R/V Investigator "CSIRO" ISAR temperature readings were compared with a National Physical Laboratory reference blackbody in laboratory tests during June 2016 and exhibited relatively low biases $(<0.15 \mathrm{~K})$ over normal operating temperatures (Theocharous et al. 2019).

The $\mathrm{SST}_{\text {depth }}$ data are measured by a SeaBird SBE 38 temperature sensor (https://www.seabird.com), located within the thermosalinograph water intake in the vessel's drop keel at a depth of approximately 7.1-9.9 m below the vessel's summer load line (depending on the position of the drop keel during the voyage). It should be noted that while the vessel is moving, the SBE 38 samples water that is entrained from a wider range of depths than 7-10 m, due to turbulence of the water around the ship's hull. The SBE 38 is calibrated on an annual basis over the range from $-1.5^{\circ}$ to $32^{\circ} \mathrm{C}$ by the Commonwealth Scientific and Industrial Research Organisation (CSIRO) Oceanographic Calibration Facility, and in September 2017 had a calibration uncertainty of around $0.002 \mathrm{~K}$, which is the $95 \%$ uncertainty interval and nearly twice the SD (CSIRO 2017). The SBE 38 temperatures are sampled every $5 \mathrm{~s}$ and averaged over each minute. In collocating with $\mathrm{SST}_{\text {skin }}$, only the simultaneously obtained $\mathrm{SST}_{\text {depth }}$ measurements are retained. The cool skin amplitude is defined as $\Delta T=\mathrm{SST}_{\text {skin }}-\mathrm{SST}_{\text {depth }}$.

The QC'd SST skin $_{\text {and }} \mathrm{SST}_{\text {depth }}$ pairs used in this study are collected from 103 days between 8 January 2016 and 4 February 2018, along Australian coastal transects with a small portion coming from cruises through the Southern Ocean to Antarctica. The ship routes, colored by the $\mathrm{SST}_{\text {depth }}$ data, are shown in Fig. 1.

\section{b. Heat fluxes}

As a contribution to IMOS, measured at the same time with SST are a suite of high-quality meteorological

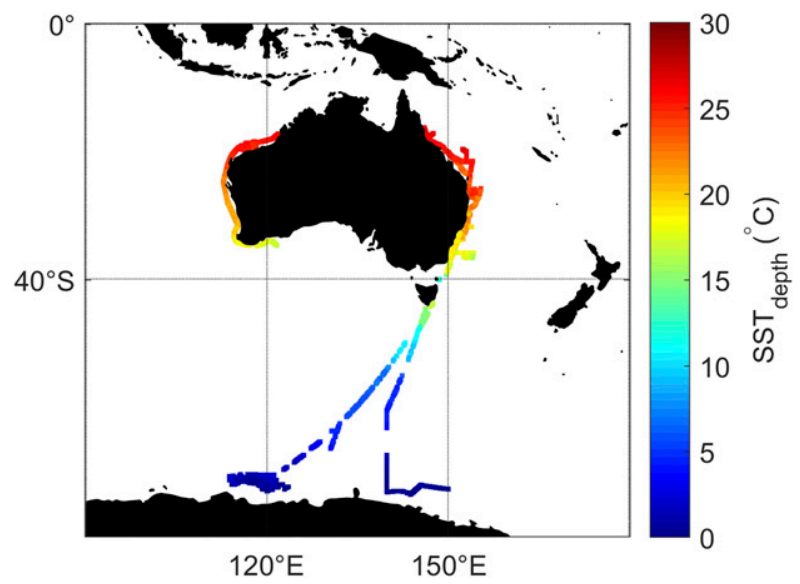

FIG. 1. Ship routes during which the data used in this study were collected. The color represents $\mathrm{SST}_{\text {depth }}$.

variables, enabling the determination of heat fluxes (http:// imos.org.au/facilities/shipsofopportunity/airseaflux/). Several variables (air temperature, relative humidity, wind speed, etc.) are measured on both port and starboard sides of the ship. Only upwind observations, that is, when the wind is coming from the front of the ship, are selected so that the effect of the ship presence on the observations can be reduced to minimum. This is realized by confining the platform-relative wind direction to $\pm 90^{\circ}$ (E. Schulz 2018, personal communication). Specifically, when the platform-relative wind direction is between $0^{\circ}$ and $90^{\circ}$ (wind coming from northeast relative to the ship's moving direction), data from the starboard (right) side sensor are retained; when the platform-relative wind direction is between $-90^{\circ}$ and $0^{\circ}$ (wind coming from northwest relative to the ship's moving direction), data from the port (left)-side sensor are selected. The true wind speed $U$ is measured at a height of $\sim 24.5 \mathrm{~m}$ above the summer load line, from which the $10-\mathrm{m}$ wind speed $U_{10}$ is computed according to Smith (1988).

We define all heat fluxes from the atmosphere into the ocean as positive, and negative otherwise. The calculations of latent heat flux $Q_{1}$ and sensible heat flux $Q_{\text {s }}$ follow the most updated version (v3.6) of the Tropical Ocean and Global Atmosphere Coupled Ocean-Atmosphere Response Experiment (TOGA COARE) bulk parameterizations but with ISAR $\mathrm{SST}_{\text {skin }}$ inputs (e.g., Fairall et al. 1996b, 2003). The net longwave radiation $Q_{\mathrm{lw}}$ is calculated as

$$
Q_{\mathrm{lw}}=\varepsilon Q_{\mathrm{lwd}}-\varepsilon \sigma T_{s}^{4}-0.036 \varepsilon Q_{\mathrm{swd}},
$$

where $\varepsilon$ is the emissivity of the seawater, $Q_{\mathrm{lwd}}$ is the measured downwelling longwave radiation, $\sigma$ is the Stefan-Boltzmann constant, $T_{s}$ is $\mathrm{SST}_{\text {skin }}$, and $Q_{\text {swd }}$ is the measured downwelling solar insolation. Note that 
$\varepsilon$ is a function of sea state and viewing angle $\theta$, which is affected by the ship's roll [refer to Wimmer and Robinson (2016) and the references therein]. In the $\mathrm{R} / \mathrm{V}$ Investigator ISAR processing system, the seawater emissivity $\varepsilon$ is set as constant at 0.9916 , based on a nadir viewing angle of $25^{\circ}$ (W. Wimmer 2016, personal communication; after Niclòs et al. 2009). The third term on the right-hand side of Eq. (1) is the correction for sensor heating for Eppley pyrgeometers used on R/V Investigator (Dickey et al. 1994).

The net heat flux within the cool skin layer is defined as $Q_{\text {net }}=Q_{1}+Q_{s}+Q_{\mathrm{lw}}$. No shortwave absorption in the skin layer is considered as we only use nighttime measurements (see section 3).

\section{c. Cool skin models}

Four published cool skin models are adopted in this study and the modeled nighttime $\Delta T$ values are compared against observations. One of the most widely used cool skin models was proposed in F96, which is based on the Saunders (1967) model but has blended free and shear-driven forced convections, and considered shortwave insolation absorption in the daytime (refer to F96 for more detail). A brief description of this physical model is as follows:

$$
\begin{aligned}
\Delta T & =\frac{Q_{\mathrm{net}} \delta}{k}, \\
\delta & =\frac{\lambda \nu}{\left(\rho_{a} / \rho\right)^{1 / 2} u_{* a}},
\end{aligned}
$$

and

$$
\lambda=6\left\{1+\left[\frac{Q_{b} 2^{4} g \alpha \rho c_{p} \nu^{3}}{u_{*_{a}}^{4}\left(\rho_{a} / \rho\right)^{2} k^{2}}\right]^{3 / 4}\right\}^{-1 / 3},
$$

where $\Delta T$ is the cool skin amplitude, $k$ is the thermal conductivity of water, $\lambda$ is the Saunders constant, $\nu$ is the kinematic viscosity, $\rho_{a}$ and $\rho$ are densities of air and seawater, respectively, $u_{*_{a}}$ is the atmospheric friction velocity, $Q_{b}$ is virtual surface cooling that includes the buoyancy effects of salinity due to evaporation, $g$ is the acceleration of gravity, $\alpha$ is the thermal expansion coefficient, and $c_{p}$ is the specific heat of water.

Three empirical parameterizations are included in this study: D02, M11, and A17. The D02 scheme is the first parameterization relating the cool skin amplitude to wind speed only, and the other two proposed different coefficients and constants using the same equation form. The three equations are as follows:

$$
\mathrm{D} 02 \Delta T=-0.14-0.30 \exp (-0.27 U),
$$

$$
\mathrm{M} 11 \Delta T=-0.13-0.724 \exp \left(-0.35 U_{10}\right),
$$

and

$$
\mathrm{A} 17 \Delta T=-0.30-0.55 \exp \left(-0.41 U_{10}\right),
$$

where $\Delta T$ is the nighttime cool skin amplitude, $U$ is the observed surface wind speed, and $U_{10}$ is the 10 -m-height wind speed.

In addition to the published models, using the same functional form as D02, a new empirical scheme with different coefficients and constants is proposed in this study, and validated together with all other parameterizations.

\section{Quality control}

\section{a. ISAR SST $T_{\text {skin }}$ uncertainty}

Before data analysis, the uncertainty of ISAR SST skin $_{\text {. }}$ measurements is first investigated. In section 2 , we set the total uncertainty threshold to $0.2 \mathrm{~K}$ after several initial tests, which retains $\sim 89.5 \%$ of all measurements [close to the $94.8 \%$ reported in Wimmer and Robinson (2016)]. This $0.2-\mathrm{K}$ threshold roughly corresponds to a quality level $\geq 4$ in the International SST Fiducial Reference Measurement Radiometer Network L2R specifications (http://www.shipborne-radiometer.org), and is quite strict for this study (W. Wimmer 2019, personal communication). However, it is known that the total uncertainty varies with the roll of the ship, which highly depends on the sea surface roughness (Wimmer and Robinson 2016). Therefore, a further investigation of the ISAR total uncertainty as a function of $U_{10}$ is conducted. The results are shown in Fig. 2.

In Fig. 2, it is observed that for $U_{10}<10 \mathrm{~m} \mathrm{~s}^{-1}$ conditions, there is no dependency of total uncertainty on $U_{10}$. The ISAR SST $_{\text {skin }}$ data have a stable, high quality with an average uncertainty of $\sim 0.12 \mathrm{~K}$. As $U_{10}$ increases to $>10 \mathrm{~m} \mathrm{~s}^{-1}$, the effect of ship roll starts to impact the total uncertainty. Before $U_{10}$ reaches $15 \mathrm{~m} \mathrm{~s}^{-1}$, the uncertainty value slightly climbs but is still well below $0.15 \mathrm{~K}$. However, for stronger wind conditions $\left(U_{10}>\right.$ $15 \mathrm{~m} \mathrm{~s}^{-1}$ ), the total uncertainty sharply rises. The $95 \%$ confidence level margin of error (MoE), that is, 1.96 times the SD divided by the square root of the collocation number, significantly increases, which is partially due to the reduced collocation numbers (Fig. 2). Hence, in addition to the $0.2-\mathrm{K}$ total uncertainty threshold, for the rest of this study, only conditions with $U_{10} \leq 15 \mathrm{~m} \mathrm{~s}^{-1}$ are retained to achieve the highest possible data quality and the most statistically robust results.

\section{b. Minimization of diurnal warming effect}

The presence of DW signals often makes it challenging to accurately determine the cool skin effect. In the 


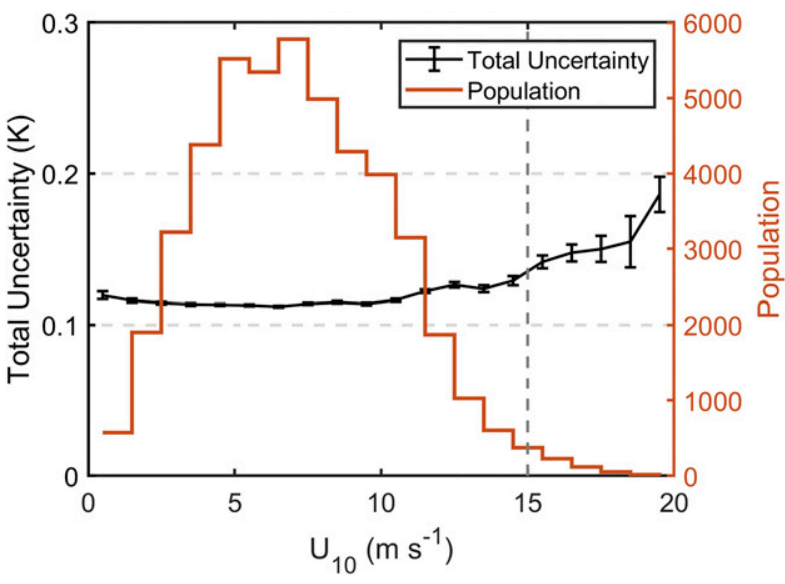

FIG. 2. The population of skin and depth SST collocations and

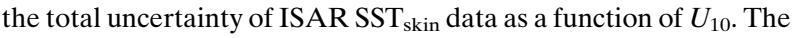
error bar of the total uncertainty is the $95 \%$ confidence level margin of error $(\mathrm{MoE})$, i.e., 1.96 times the standard deviation divided by the square root of the collocation number. A reference line at $U_{10}=15 \mathrm{~m} \mathrm{~s}^{-1}$ is shown (vertical dashed line).

daytime, especially under calm winds and strong solar insolation, the small amplitude skin effect is easily overwhelmed by DW events (affecting both $\mathrm{SST}_{\text {skin }}$ and $\mathrm{SST}_{\text {subskin }}$ ) with often much larger amplitudes. Hence, it is required that to measure the skin effect the concurrent $\mathrm{SST}_{\text {depth }}$ measurements should be no deeper than a few centimeters in the daytime (M11). To avoid such complexity, many studies have adopted nighttime data only. Due to the deep (7-10 m) SST depth measurements in this study, we also use only nighttime collocations. Nighttime is defined here as when the absolute value of solar zenith angle, $|\mathrm{SZA}|$, is $>110^{\circ}$ before local midnight, and $>90^{\circ}$ before dawn. The threshold of $110^{\circ}$ being slightly larger than $90^{\circ}$ in the afternoon is to further avoid possible DW contamination shortly after sunset.

The assumption that $\mathrm{SST}_{\text {depth }}$ represents $\mathrm{SST}_{\text {subskin }}$ is only valid under well-mixed conditions. D02 proposed that the upper layers (at least upper $5 \mathrm{~m}$ as shown in their study) can be treated as well mixed under $U_{10}>6(2) \mathrm{m} \mathrm{s}^{-1}$ conditions for daytime (nighttime), which has been widely accepted especially in the satellite SST validation field. However, this assumption is verified first in this study before being adopted.

In Fig. 3a, nighttime $\Delta T$ is plotted against $U_{10}$, with its color representing the corresponding $Q_{\text {net. }}$. In general, the distribution pattern is very similar to the findings in previous studies (e.g., D02; M11). Larger $Q_{\text {net }}$ events are more often seen at the higher $U_{10}$ end, as expected, due to an increased $Q_{1}$. However, there are many positive $\Delta T$ values for $U_{10}<8 \mathrm{~m} \mathrm{~s}^{-1}$ conditions. A case study is then conducted to verify whether these are DW signal residuals: the $>0.2-\mathrm{K} \Delta T$ values under $U_{10}>6 \mathrm{~m} \mathrm{~s}^{-1}$ conditions are analyzed (within the black box in Fig. 3a). Interestingly, 16 out of these 28 values are from the same night, 31 October-1 November 2017, which are shown in Fig. 3b. Clearly, there was a very strong DW event occurring in the local afternoon of 31 October 2017 with a maximum amplitude close to $3 \mathrm{~K}$. The DW residual persists almost to the following dawn. Although there was a sudden $U_{10}$ increase in the early morning of 1 November 2017 (from $\sim 0200$ to 0600 LST), the $\Delta T$ values are still positive. This indicates that these positive $\Delta T$ values are a result of the DW residuals, rather than "warm skin" in this case, as $\Delta T$ reaches again $\sim-0.22 \mathrm{~K}$ at dawn on 1 November 2017. Therefore, although the assumption of "well mixed" is generally true for night conditions with $U_{10}>2 \mathrm{~m} \mathrm{~s}^{-1}$, extremely large DW events can escape a $U_{10}>2 \mathrm{~m} \mathrm{~s}^{-1}$, or even $>6 \mathrm{~m} \mathrm{~s}^{-1}$ filter, leading to an illusory "warm skin." Furthermore, applying a $U_{10}$-condition filter significantly reduces the available data. Only $57.6 \%$ (8256 out of 14338 ; Fig. 3a) of the pairs are retained if $U_{10}$ is confined to $>6 \mathrm{~m} \mathrm{~s}^{-1}$. Another approach to minimize the DW effect and also to retain the night $U_{10}<2$ or $<6 \mathrm{~m} \mathrm{~s}^{-1}$ data is to select only the nights that have a daytime $\left(|\mathrm{SZA}|<90^{\circ}\right)$ average $U_{10}>6 \mathrm{~m} \mathrm{~s}^{-1}$. Figure $3 \mathrm{c}$ shows that, as expected, nearly all DW residuals, that is, positive $\Delta T$ values, are eliminated, and nighttime data at all wind conditions are retained. However, a significant drawback is that the available population has sharply decreased (to 5410), especially for $U_{10}<4 \mathrm{~m} \mathrm{~s}^{-1}$ conditions.

Hence, in this study, instead of pursuing obtaining well-mixed conditions with $U_{10}$ constraints, we turned to another approach. We applied directly the filter of the maximum DW within a local day, $\mathrm{DW}_{\text {max }}\left(\mathrm{SST}_{\text {skin }}-\right.$ $\mathrm{SST}_{\text {depth }}$ ). If the $\mathrm{DW}_{\text {max }}$ is smaller than a certain threshold, the nighttime data within that day will be retained. However, a further problem arises, which is the travel of the ship over this period. The environmental conditions of the daytime measurements, which are used to calculate $\mathrm{DW}_{\text {max }}$, could be different than those of the nighttime data because the ship may have traveled a long distance during this period. Thus, the travel distance of the ship is first investigated. Figure 4a shows that in $95.9 \%$ (92.6\%) of the total days, the ship has traveled by less than $1^{\circ}$ in latitude (longitude) direction, and $85.1 \%$ of the days within a $1^{\circ} \times 1^{\circ}$ longitude-latitude box ( $<1^{\circ}$ in both directions).

A series of tests are then conducted to determine both the $\mathrm{DW}_{\max }$ threshold and the maximum ship travel distance, and the results indicate that the best restraints are that $\mathrm{DW}_{\max }$ is $<0.3 \mathrm{~K}$ and the ship's travel during a local day is within a $1^{\circ} \times 1^{\circ}$ longitude-latitude box (Fig. 4b). The number of $\Delta T$ values is 7239 . The $0.3-\mathrm{K}$ threshold is chosen because it is close to 1.5 times the ISAR total uncertainty, that is, 3 times the $\mathrm{SD}$, allowing room for 
(a)

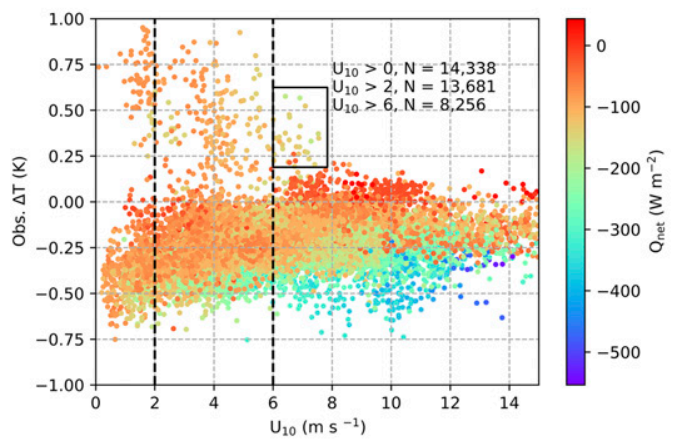

(b)

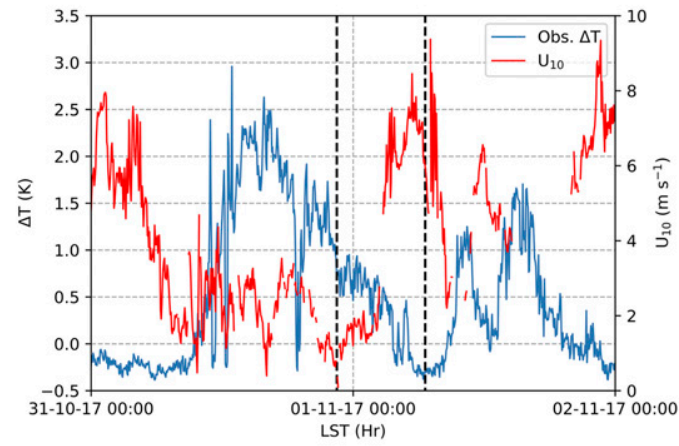

(c)

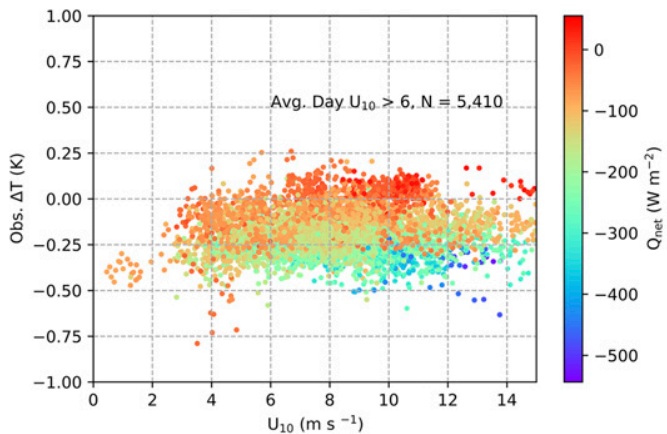

FIG. 3. (a) The distribution of nighttime $\Delta T$ values as a function of $U_{10}$. Color indicates the corresponding net heat flux $Q_{\text {net }}$. Populations of $\Delta T$ under different $U_{10}$ filters are shown. The two dashed vertical lines mark $U_{10}=2$ and $6 \mathrm{~m} \mathrm{~s}^{-1}$. (b) A case study of $\Delta T$ values within the black box in (a) to verify whether they are DW residuals. The two dashed vertical lines mark the nighttime period. (c) As in (a), but for nighttime $\Delta T$ values when the corresponding daytime $\left(|\mathrm{SZA}|<90^{\circ}\right)$ average $U_{10}>6 \mathrm{~m} \mathrm{~s}^{-1}$.

data noise and potential warm skin events. If we increase this threshold to, say $0.5 \mathrm{~K}$, the available measurements only increase by $\sim 1.0 \%$ (from 7239 to 7310 ) and a large portion of the extra measurements might be DW signals. Similarly, if we further reduce the box size to, say $0.5^{\circ} \times 0.5^{\circ}$, the distribution pattern of $\Delta T$ values is much alike Fig. $4 \mathrm{~b}$ from visual judgment, yet the available data amount is significantly reduced by $40.9 \%$ (from 7239 to 4281 ).

Now, we obtained a dataset with minimum DW residuals, and of large quantity (7239) at all wind conditions (a)

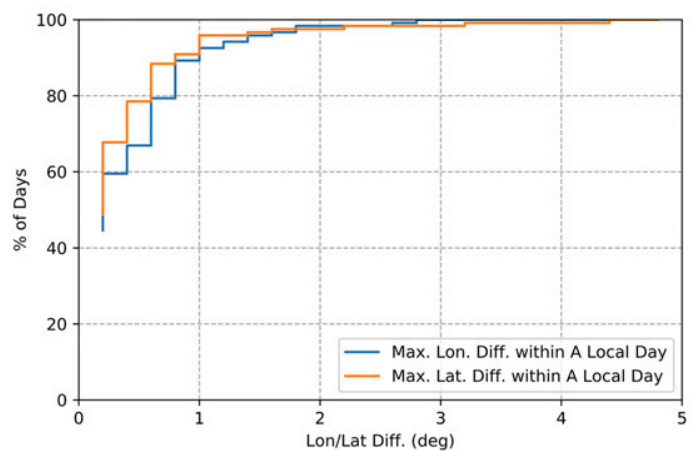

(b)

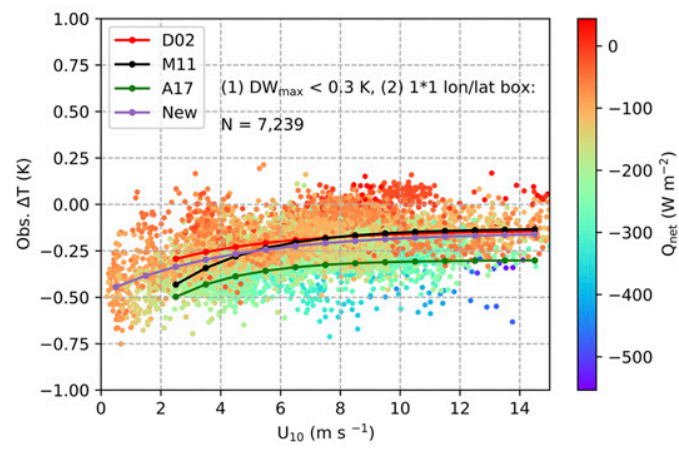

FIG. 4. (a) The accumulated percentage of total days against the travel distance of the ship within a local day. The distance the ship travels is indicated by the maximum daily longitude and latitude differences (step is $0.2^{\circ}$ ). (b) Distribution of nighttime $\Delta T$ values when maximum DW values within a local day is $<0.3 \mathrm{~K}$ and the ship travels within a $1^{\circ} \times 1^{\circ}$ lon-lat box. The lines in (b) are the empirical models including D02 (red), M11 (black), A17 (green), and the new one generated from this study (purple). 
TABLE 1. A comparison between the ship experiments for different empirical models. Note that M-AERI stands for Marine-Atmospheric Emitted Radiance Interferometer, and SISTeR stands for Scanning Infrared Sea Surface Temperature Radiometer.

\begin{tabular}{|c|c|c|c|c|c|c|c|}
\hline Model & $\mathrm{SST}_{\text {skin }}$ radiometer & $\begin{array}{c}\mathrm{SST}_{\text {depth }} \\
\text { depth }\end{array}$ & Latitude range & Night or day & $\begin{array}{l}\text { Seasons } \\
\text { covered }\end{array}$ & $\begin{array}{c}\text { Open } \\
\text { ocean? }\end{array}$ & $\begin{array}{c}\text { Data } \\
\text { counts }\end{array}$ \\
\hline D02 & M-AERI, DAR011, SISTeR & $1-5 \mathrm{~m}$ & $\sim 50^{\circ} \mathrm{S}-48^{\circ} \mathrm{N}$ & Night & All seasons & Yes & 2607 \\
\hline M11 & M-AERI & $\sim 5 \mathrm{~cm}$ & $41^{\circ}-48^{\circ} \mathrm{S}$ & Day and night & Austral autumn & Yes & 311 \\
\hline A17 & ISAR & $1 \mathrm{~m}$ & $36^{\circ}-37^{\circ} \mathrm{N}$ & Day and night & Autumn & No & 2123 \\
\hline New & ISAR & $7-10 \mathrm{~m}$ & $17^{\circ}-66^{\circ} \mathrm{S}$ & Night & All seasons & Yes & 7239 \\
\hline
\end{tabular}

(Fig. 4b). All the following analyses are based on this dataset.

\section{Results}

\section{a. A new empirical model}

Having gained more confidence in the data after careful quality control and DW minimization steps, we first recalculated the parameters of the functional form proposed in D02:

$$
\text { New } \Delta T=-0.15-0.33 \exp \left(-0.23 U_{10}\right) \text {. }
$$

This parameterization is plotted along with the three published empirical functions in Fig. 4b. It is observed that the new model agrees well with D02 and M11 for $U_{10}>5 \mathrm{~m} \mathrm{~s}^{-1}$ conditions. For $U_{10}$ between 2 and $5 \mathrm{~m} \mathrm{~s}^{-1}$, the new model and D02 have very similar $\Delta T$ values, while M11 overestimates the cool skin amplitude. Over the whole $U_{10}$ range, A17 is significantly overestimating the $\Delta T$ amplitude. Furthermore, although turbulent shear-driven heat transfer diminishes and convective and molecular heat transfer processes dominate when $U_{10}$ is $<2 \mathrm{~m} \mathrm{~s}^{-1}$ (Saunders 1967), we believe it is reasonable to apply this new model to such calm conditions thanks to the abundant measurements.

This new scheme will be analyzed along with other models in the following section. To facilitate the interpretation of the intercomparison between empirical models, a comparison of the ship experiments for all empirical schemes is conducted and the results are shown in Table 1. The ship measurements from D02 and this study cover all seasons spanning relatively large latitudinal ranges, yet only nighttime data are included. M11 and A17 have both daytime and nighttime measurements. However, they have fewer data over a small spatial domain. In addition, A17 experiment was conducted along coastal waters.

\section{b. Statistics}

In this section, analyses of observed and modeled cool skin signals are conducted together to validate the schemes, including the physical F96 model and all empirical parameterizations.

The distributions of the observed and modeled $\Delta T$ values and their basic statistics are shown in Fig. 5. The shape and statistics of the observed $\Delta T$ are in good agreement with the observations from previous studies, such as M11 (their Fig. 2), which has a $-0.20-\mathrm{K}$ mean and a $0.13-\mathrm{K} \mathrm{SD}$. The F96 model shares a similar pattern with observations but with several differences (Fig. 5a). They have very close statistics, except that the observed mean $\Delta T(-0.23 \mathrm{~K})$ is about $0.04 \mathrm{~K}$ larger in amplitude than the F96 $\Delta T(-0.19 \mathrm{~K})$. Another difference is in the peak values: observed ISAR $\Delta T$ has a peak value between -0.22 and $-0.24 \mathrm{~K}$, whereas the most populous F96 $\Delta T$ values are seen between -0.16 and $-0.18 \mathrm{~K}$. In addition, there are many more small amplitude $\Delta T$ values $(-0.05$ to $-0.20 \mathrm{~K})$ in F96 than in observations, and no positive $\Delta T$ values at all as warm skin is considered not "physical" in F96.

The distribution patterns of the empirical parameterizations are different from that of observations or F96. However, due to the same functional form, their patterns are quite similar (Fig. 5b). The nonnormal distribution does not make total physical sense, especially with a threshold [e.g., $-0.14 \mathrm{~K}$ for D02 as the first coefficient term on the right in Eq. (3a)] above which there are no $\Delta T$ values at all. Nonetheless, very basic statistical features of the cool skin effect can be captured. For example, the mean $\Delta T$ values of D02 $(-0.20 \mathrm{~K})$, M11 $(-0.22 \mathrm{~K})$, and the new one $(-0.23 \mathrm{~K})$ are close to observations and F96. However, A17 overestimates the skin effect compared with other models, which may be because a calibration offset of $>0.1 \mathrm{~K}$ existed between their ISAR skin SST and thermistor $1 \mathrm{~m}$ depth SST, which was not corrected during postcruise calibration or postprocessing, but could also be due to coastal effects as their dataset used to tune the coefficients were obtained from coastal regions rather than open waters (A17).

Due to the less satisfying behaviors of the empirical models, hereafter, they are not included in the following analyses. Only F96 is retained to be further validated.

\section{c. Dependency of $\Delta T$ on environmental conditions}

\section{1) WIND SPEED}

The dependency of skin effect on $U_{10}$ is shown in Fig. 6. Different from Fig. $4 \mathrm{~b}$ in which fitted curves are 
(a)

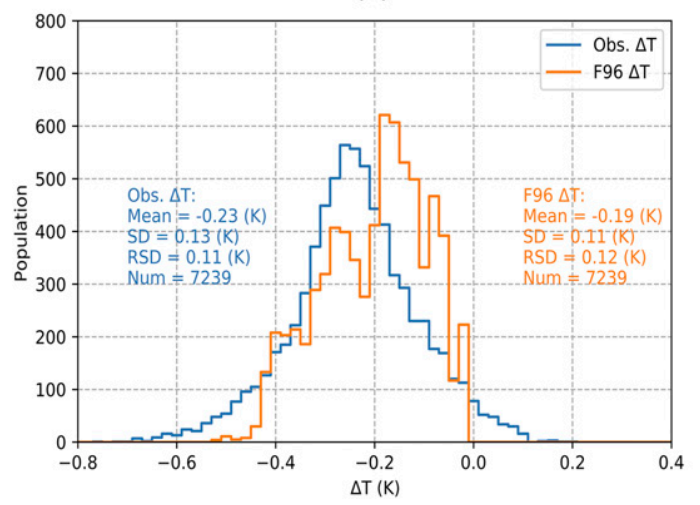

(b)

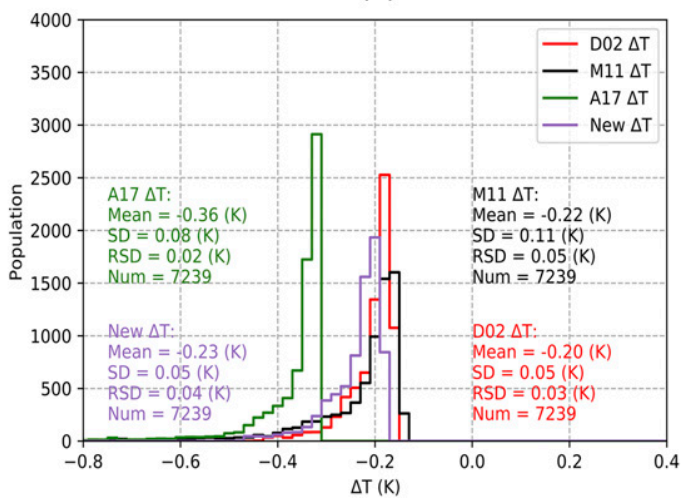

FIG. 5. (a) The distribution of observed and F96 modeled $\Delta T$. Statistics shown include the mean value, SD, robust SD (RSD), and the total number of $\Delta T$ values. (b) As in (a), but for the empirical functions: D02 (red), M11 (black), A17 (green), and the new function proposed in this study (purple).

plotted, Fig. 6 shows the mean values of observed and F96 modeled $\Delta T$ for each $1 \mathrm{~m} \mathrm{~s}^{-1} U_{10}$ bin. For conditions with $U_{10}<2 \mathrm{~m} \mathrm{~s}^{-1}$, F96 is underestimating the cool skin amplitude by $\sim 0.03$ to $\sim 0.10 \mathrm{~K}$. For $U_{10}$ between 2 and $8 \mathrm{~m} \mathrm{~s}^{-1}$, F96 mean $\Delta T$ values are close to observations. However, the observed mean $\Delta T$ values start to level off at $\sim-0.20 \mathrm{~K}$ when $U_{10}$ exceeds $8 \mathrm{~m} \mathrm{~s}^{-1}$, yet $\mathrm{F} 96$ continues to display a steady climbing trend before reaching $\sim-0.05 \mathrm{~K}$ at $U_{10}=15 \mathrm{~m} \mathrm{~s}^{-1}$. It is a bit surprising to observe a slight increase trend in observation when $U_{10}>12 \mathrm{~m} \mathrm{~s}^{-1}$. One possible reason is that these strong winds are more often seen at high latitudes where the SST is cold $\left(<10^{\circ} \mathrm{C}\right)$ and $\Delta T$ of small amplitude (see Fig. 8 and section 5).

\section{2) HeAt FluXes}

The dependencies of $\Delta T$ on heat fluxes are investigated, including the net heat flux $Q_{\text {net }}$ (Fig. 7a), latent heat flux $Q_{l}$ (Fig. 7b), longwave heat flux $Q_{\text {lw }}$ (Fig. 7c), and sensible heat flux $Q_{s}$ (Fig. 7d). In this study, the heat flux from the atmosphere to the ocean is defined as positive, and negative otherwise. Figure 7 a shows that there is a clear positive correlation between the observed $\Delta T$ and $Q_{\text {net }}$, with the coolest skin $(-0.34 \mathrm{~K})$ corresponding to the most negative $Q_{\text {net }}\left(-350\right.$ to $\left.-400 \mathrm{~W} \mathrm{~m}^{-2}\right)$ and near-zero $\Delta T$ values when $Q_{\text {net }}$ is close to zero or even slightly positive. For $Q_{\text {net }}$ below $-200 \mathrm{~W} \mathrm{~m}^{-2}, \Delta T$ is relatively stable at around $-0.30 \mathrm{~K}$, whereas $\Delta T$ steadily climbs up together with $Q_{\text {net }}$ when $Q_{\text {net }}$ is above $-200 \mathrm{~W} \mathrm{~m}^{-2}$. It is encouraging to see that F96 is able to capture all these features, except that there is a consistent underestimation of $\Delta T$ magnitude (by $\sim 0.04-0.06 \mathrm{~K}$ ) for $Q_{\text {net }}>-200 \mathrm{~W} \mathrm{~m}^{-2}$ conditions.

The dependency of $\Delta T$ on individual types of heat flux shows similar results. Figure $7 \mathrm{~b}$ indicates that there is nearly an exponential relationship between $\Delta T$ and $Q_{l}$ for $Q_{l}>-300 \mathrm{~W} \mathrm{~m}^{-2}$, which is observed in F96 as well. For $Q_{l}<-300 \mathrm{~W} \mathrm{~m}^{-2}$, large differences between observed and F96 $\Delta T$ exist. Nonetheless, the very small collocation numbers make it challenging to reach any robust conclusions. In Fig. 7c, the near-linear positive relationship between $Q_{\mathrm{lw}}$ and $\Delta T$ is observed. F96 successfully displays a similar pattern but with a small underestimation (by $\sim 0.04-0.06 \mathrm{~K}$ ) for most $Q_{\mathrm{lw}}$ conditions. The correlation between observed $\Delta T$ and $Q_{s}$ is somewhat weak (Fig. 7d). This is largely because most of the $Q_{s}$ values are within a narrow range of between -20 and $10 \mathrm{~W} \mathrm{~m}^{-2}$. Although with larger uncertainties, the trends of F96 and observation $\Delta T$ are still in reasonable agreement (Fig. 7d).

\section{3) Temperatures}

Given the good relationship between $Q_{\mathrm{lw}}$ and $\Delta T$ observed in Fig. 7c, and that $Q_{\mathrm{lw}}$ is closely related to

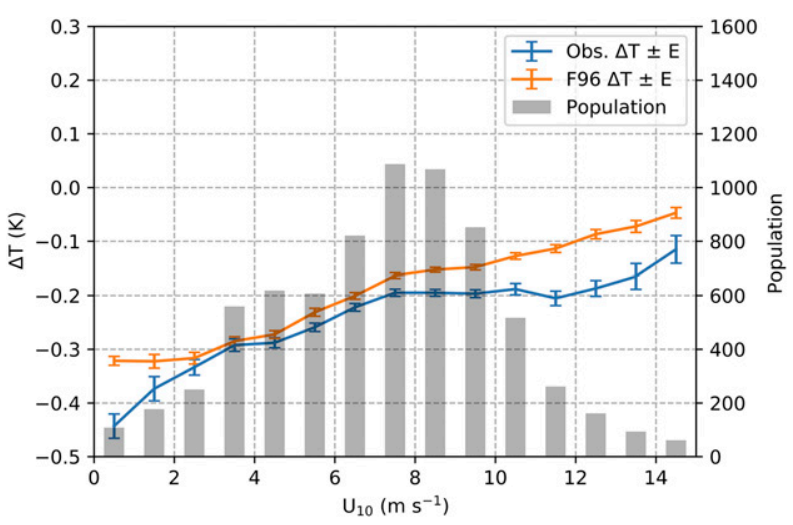

FIG. 6. Observed and F96 $\Delta T$ as a function of $U_{10}$. The error bar on observed (blue) and F96 (orange) $\Delta T$ is the $95 \%$ confidence MoE. The gray bars represent the collocation numbers within each $1 \mathrm{~m} \mathrm{~s}^{-1} U_{10}$ bin. 

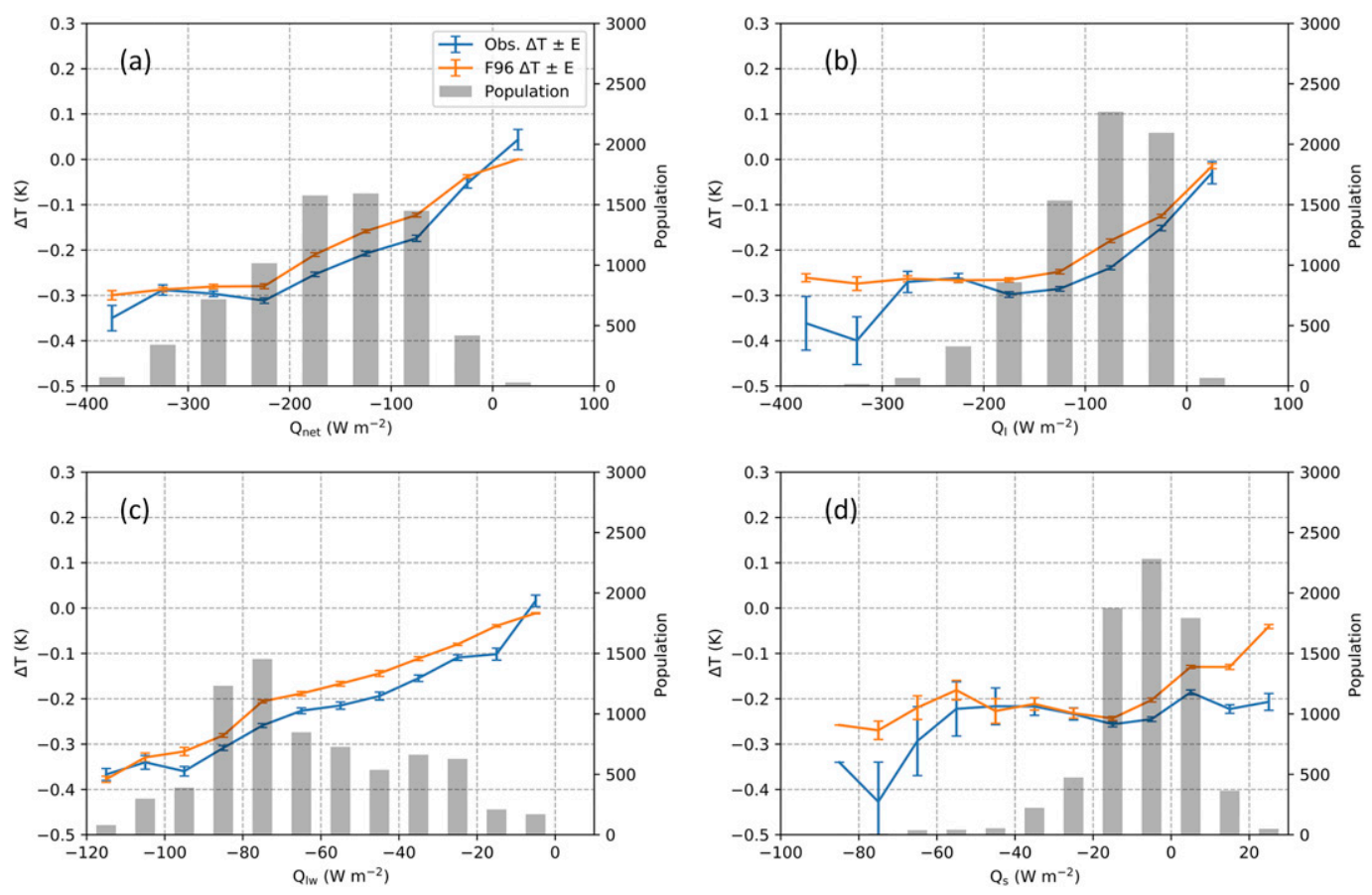

FIG. 7. As in Fig. 6, but for (a) $Q_{\text {net }}$, (b) $Q_{l}$, (c) $Q_{\mathrm{lw}}$, and (d) $Q_{s}$.

SST, the dependency of skin effect on $\mathrm{SST}_{\text {skin }}$ is further analyzed (Fig. 8a). M11 reported that there may be a dependency of cool skin amplitude on ocean temperature. Yet with only 311 measurements, no more conclusive comments were made. With significantly more data (7239) measured under SST conditions ranging from $0^{\circ}$ to $27^{\circ} \mathrm{C}$, this study provides a valuable chance to further investigate this dependency. Figure $8 \mathrm{a}$ shows that the average observed $\Delta T$ is between -0.10 and $0 \mathrm{~K}$ for conditions with $\mathrm{SST}_{\text {skin }}$ between $0^{\circ}$ and $5^{\circ} \mathrm{C}$, and increases to -0.20 to $-0.35 \mathrm{~K}$ when $\mathrm{SST}_{\text {skin }}>15^{\circ} \mathrm{C}$. Furthermore, when $\mathrm{SST}_{\text {skin }}$ rises from $24^{\circ}$ to $27^{\circ} \mathrm{C}$, under which condition the majority of the measurements were made, $\Delta T$ amplitude steadily increases from $\sim-0.23$ to $\sim-0.27 \mathrm{~K}$.
As few accurate skin SST observations were made under conditions when $\mathrm{SST}_{\text {skin }}$ is between $2^{\circ}$ and $17^{\circ} \mathrm{C}$, no conclusion can be reached for this temperature range. Nonetheless, based on Fig. 8a, together with the strong $\Delta T-Q_{\mathrm{lw}}$ relationship revealed in Fig. $7 \mathrm{c}$, it is reasonable to assume that there is a positive relationship between $\Delta T$ and sea temperatures: warmer waters are more often covered by cooler skins. The dependency of $\Delta T$ on latitudes tells a similar story (Fig. 8b). Note that there may be other parameters and processes that could be correlated or coupled with SST that are the true cause of the increase in $\Delta T$, such as the kinematic viscosity of seawater (which decreases by $\sim 28 \%$ when going from $20^{\circ}$ to $10^{\circ} \mathrm{C}$; M11). (a)

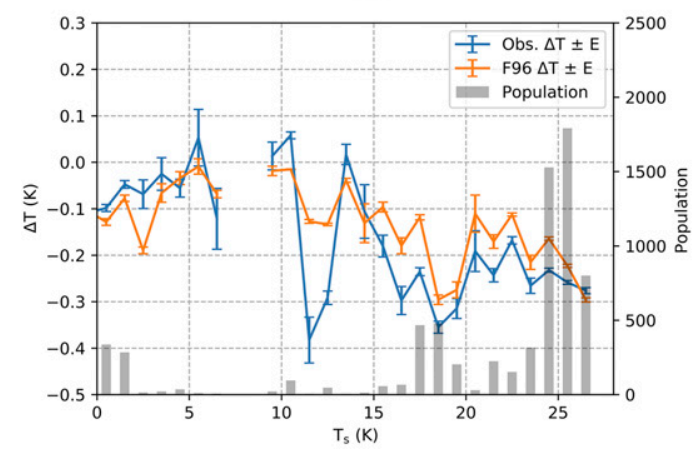

(b)

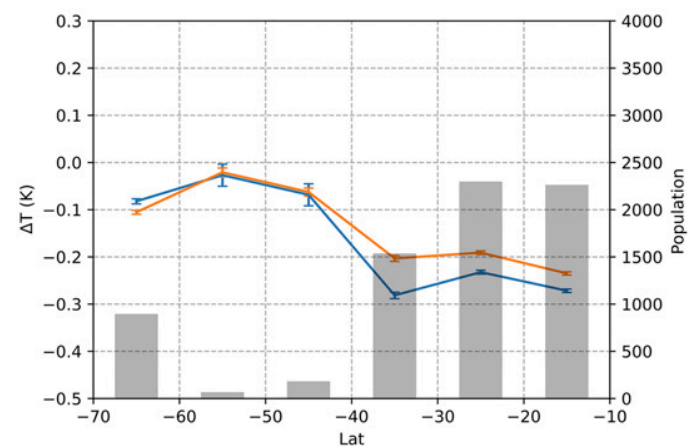

FIG. 8. As in Fig. 6, but for (a) $T_{\mathrm{s}}$, and (b) latitudes. 
(a)

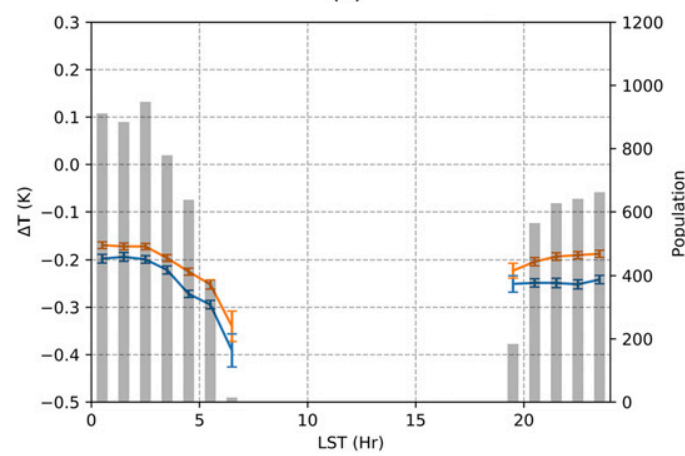

(b)

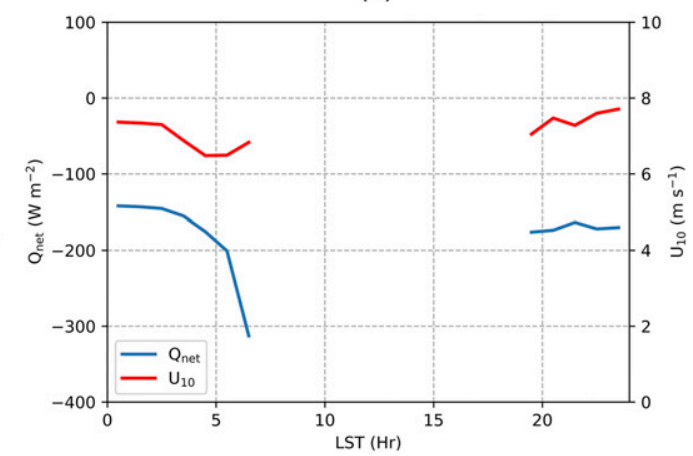

FIG. 9. (a) Dependency of $\Delta T$ on the local solar time (LST). Only nighttime hours (see the definition of nighttime in section 3) are shown. (b) Time series of nighttime $U_{10}$ and $Q_{\text {net }}$.

\section{4) LOCAL TIME}

It is known that the daytime cool skin amplitude can be different, typically smaller, than the nighttime due to the absorbed solar heating in the skin layer (e.g., F96; Wick et al. 2005). Many studies assume that the cool skin effect is consistent throughout the night and therefore do not differentiate the exact local night hours. Wilson et al. (2013) found that the cool skin amplitude is largest at around sunrise based on in situ measurements made on Lake Tahoe, which motivated us to check the cool skin-effect variation overnight in the open ocean. The results are shown in Fig. 9. As expected, $\Delta T$ is relatively stable before midnight with an average value of -0.22 to $-0.26 \mathrm{~K}$ (Fig. 9a). However, after midnight, the cool skin magnitude starts to increase from $\sim-0.20 \mathrm{~K}$ at $0100 \mathrm{LST}$ to $\sim-0.37 \mathrm{~K}$ at $\sim 0600 \mathrm{LST}$ (around dawn). This is in good agreement with the findings in Wilson et al. (2013). The corresponding more negative $Q_{\text {net }}$ in the early morning largely explains the increasing $\Delta T$ amplitude (Fig. 9b). The F96 model displays excellent performance in this regard, although with some underestimation (by $0.03-0.06 \mathrm{~K}$ ) for most of the hours. It is not known to us at this point why there is a minor jump in both $\Delta T$ and $Q_{\text {net }}$ at midnight.

\section{d. Comparison between F96 and observations}

To further validate the F96 model, an overall comparison between F96 modeled and observed $\Delta T$ is conducted (Fig. 10). In general, F96 is in close agreement with observations, as also demonstrated earlier. The mean difference between F96 and observed $\Delta T$ is $0.04 \mathrm{~K}$. This underestimation of $\Delta T$ amplitude in F96 has also been shown under different conditions (Figs. 7-9). The 0.72 correlation coefficient between the two $\Delta T$ values is relatively high, compared to previous findings such as $R=0.36$ in Castro et al. (2003).

\section{e. Is there a "warm skin"?}

As can be seen from both Figs. 5a and 10, there are positive observed $\Delta T$ values, which account for $3.7 \%$ (265 out of 7239) of all measurements. Nonetheless, given their small magnitudes (mostly $<0.20 \mathrm{~K}$ ) and the relatively large ISAR SST skin $_{\text {data }}$ uncertainty, they are not necessarily real warm skin events. This subsection will explore the physical evidence of warm skin through investigating two scenarios: 1) positive $\Delta T$ values and 2) positive $Q_{\text {net }}$ conditions.

The 265 positive $\Delta T$ values are distributed unevenly throughout the study period. Many measurements cluster on several certain days. Therefore, a case study is conducted for the night on 22 and 23 January 2017 LST, which has recorded 50 positive $\Delta T$ values (Fig. 11). These measurements were made at high latitudes $\left(\sim 64.5^{\circ} \mathrm{S}\right)$. The observed $\Delta T$ being close to zero over both day and night indicates that the upper layers are very well mixed, which can be expected with $U_{10}$ being $>6 \mathrm{~m} \mathrm{~s}^{-1}$ for most of the time (Fig. 11a). Over the whole period, $Q_{\text {net }}$ is of relatively small magnitude (Fig. 11b). Values of $Q_{s}$ are mostly positive due to the warmer air temperature compared with the sea surface. The sudden drop in $Q_{\mathrm{lw}}$, hence $Q_{\text {net }}$, in the nighttime could be due to a sudden $\mathrm{SST}_{\text {skin }}$ decrease from $\sim 1^{\circ}$ to near $0^{\circ} \mathrm{C}$. With $Q_{\text {net }}$ still being negative and these positive $\Delta T$ values having amplitudes of $\sim 0.1 \mathrm{~K}$, it is hard to discern whether these are real warm skin events because they are within the data uncertainty, which has an average value of $0.12 \mathrm{~K}$ for the 265 ISAR SST $_{\text {skin }}$ measurements.

We then investigated the behaviors of $\Delta T$ values when $Q_{\text {net }}$ is positive (Fig. 12). First, it should be noted that only $0.4 \%$ (29 out of 7239 ) of all data were made under positive $Q_{\text {net }}$ conditions. However, the results are encouraging. When $Q_{\text {net }}$ is from the atmosphere to the ocean, $86.2 \%$ ( 25 out of 29 ) of all $\Delta T$ values are positive, indicating a warm skin (Fig. 12a). All $U_{10}$ being $>8 \mathrm{~m} \mathrm{~s}^{-1}$ 


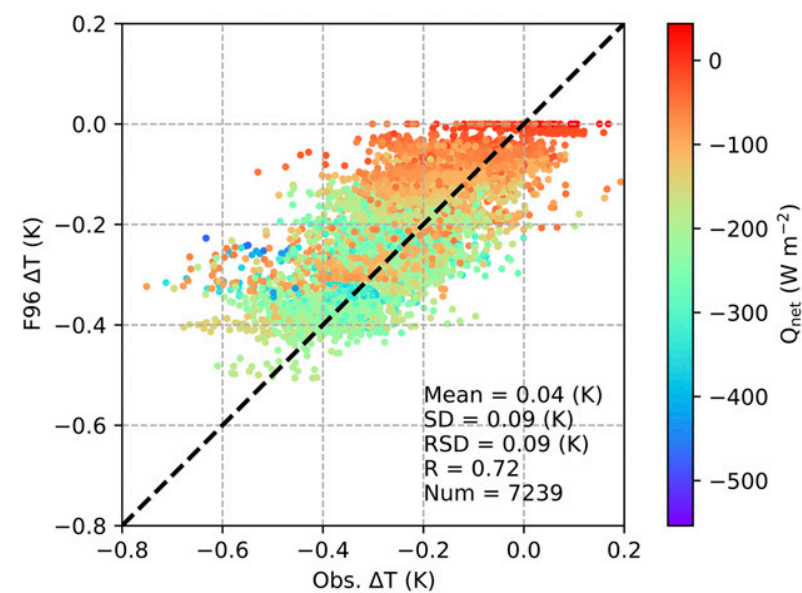

FIG. 10. Scatterplot of the collocated observed and F96 $\Delta T$ values. The black dashed line is the 1:1 reference line. The color indicates the corresponding $Q_{\text {net }}$. Statistics of the differences between F96 and observed (F96 - observed) $\Delta T$ are shown, including the mean, SD, RSD, and correlation coefficient $R$.

ensures a well-mixed upper layer, practically excluding any contamination of DW signals (Fig. 12a). Although the wind is strong, all the latent heat $\left(Q_{1}\right)$ values are positive because of the very high humidity (Fig. 12b). For the 29 cases, the average relative humidity is $97.7 \%$ with a minimum of $95.9 \%$ and maximum of $99.3 \%$, while this value may fall anywhere between $31.6 \%$ and $100 \%$ with an average of $78.2 \%$ for the whole dataset (7239). In addition, all air temperatures are warmer than $\mathrm{SST}_{\text {skin }}$, therefore the positive $Q_{s}$ values (Figs. 12a,b). Figure $12 \mathrm{c}$ also shows that $96.9 \%$ (28 out of 29 ) of the warm skin cases are observed at higher latitudes with skin SST $<10^{\circ} \mathrm{C}$, which should explain the small $Q_{\mathrm{lw}}$ amplitudes (Fig. 12b). Overall, although with a small sample size, we believe that these warm skin signals are obtained under appropriately physical conditions, hence trustworthy.

\section{Discussion and conclusions}

Using ISAR SST skin $_{\text {and concurrent }} \mathrm{SST}_{\text {depth }}$ measurements (at 7-10-m depths) obtained between 8 January 2016 and 4 February 2018 onboard Australia's Marine National Facility, R/V Investigator, this study has investigated the cool skin behavior along Australian coasts and across the Southern Ocean to near Antarctica. After careful quality control and minimization of possible diurnal warming contamination, the cool skin dataset is analyzed in detail. Modeled skin effects by a widely applied F96 cool skin scheme and three empirical parameterizations are compared with the observations. A new empirical model using D02 functional form is also proposed.

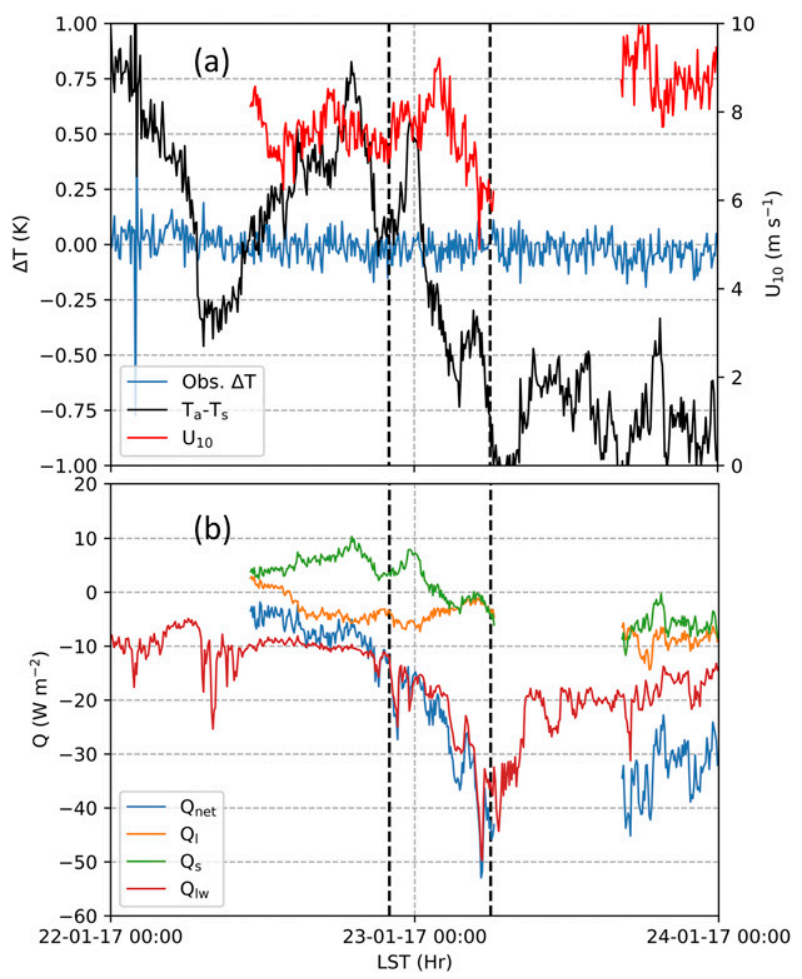

FIG. 11. (a) The observed $\Delta T$ (blue), air-sea temperature difference $T_{a}-T_{s}$ (black), and $U_{10}$ (red) for two days from 22 to 23 Jan 2017 LST. (b) As in (a), but for heat fluxes. The black dashed lines indicate the nighttime period.

Key conclusions can be summarized as below:

1) It is generally true that during nighttime when $U_{10}>$ $2 \mathrm{~m} \mathrm{~s}^{-1}$, the upper ocean layers are well mixed, that is, a $\mathrm{SST}_{\text {depth }}$ measured at a certain depth can practically represent $\mathrm{SST}_{\text {subskin }}$ (D02). However, as shown in this study, very strong DW events can persist well until the next dawn. It is recommended that for cool skin studies, before simply applying a certain $U_{10}$ filter $\left(U_{10}>2\right.$ or $\left.>6 \mathrm{~m} \mathrm{~s}^{-1}\right)$, if possible, one should try to select nighttime data based on the corresponding daytime $\mathrm{DW}_{\text {max }}$ amplitudes of the same water mass. More measurements can be retained this way, especially for calm wind conditions.

2) It has been noticed that the near-symmetric Gaussian distribution pattern of the observed $\Delta T$ values is slightly different than those in previous studies, which are often negatively skewed, such as Fig. 2 in M11. This indicates that we have more small amplitude cool skin signals $(\Delta T>-0.20 \mathrm{~K})$. We believe that the major reason is due to the incorporation of higher-latitude regions $\left(>60^{\circ} \mathrm{S}\right)$ in this study, where $\Delta T$ amplitudes are usually smaller. We then investigated the $\Delta T$ distribution pattern for SST $>15^{\circ} \mathrm{C}$ conditions only. As expected, the right tail $(\Delta T>-0.20 \mathrm{~K})$ 
(a)

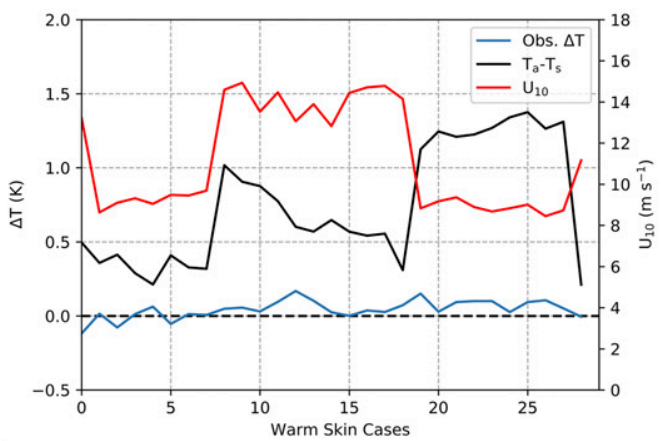

(b)

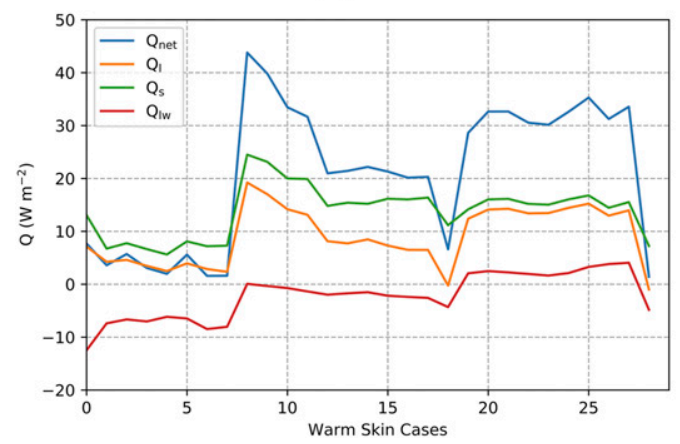

(c)

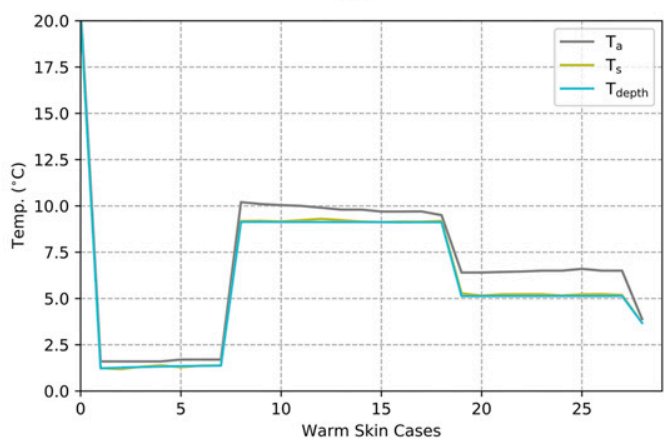

FIG. 12. (a) The observed $\Delta T$ (blue), $T_{a}-T_{s}$ (black), and $U_{10}$ (red) for positive $Q_{\text {net }}$ conditions, which consists of 29 cases. (b) Net and individual heat flux for the 29 cases. (c) Separately plotted three temperatures: air temperature $T_{a}$ (gray), skin SST $T_{s}$ (brown), and depth SST $T_{\text {depth }}$ (green).

is significantly thinner, and the distribution is more negatively skewed (not shown). The inclusion of highlatitude regions should also be largely responsible for the climbing trend of observed $\Delta T$ when $U_{10}>12 \mathrm{~m} \mathrm{~s}^{-1}$ given their relatively strong wind conditions.

3) Although our $\Delta T$ statistics are generally consistent with previous findings, minor differences still exist due to many reasons. First, we have more measurements covering a much larger latitude range and all seasons. Second, despite of careful quality control, uncertainties in both $\mathrm{R} / \mathrm{V}$ Investigator $\mathrm{ISAR} \mathrm{SST}_{\text {skin }}$ and $\mathrm{SST}_{\text {depth }}$ may still exist due to factors such as differing $\mathrm{SST}_{\text {skin }}$ and $\mathrm{SST}_{\text {depth }}$ sensor calibrations. Measurement errors from other variables (e.g., air temperature, relative humidity, and wind speed) may all be contributing factors. We are also aware that the heat fluxes calculated using TOGA COARE bulk parameterizations have their uncertainties as well. Nevertheless, the errors tend to be small (within a few percent against direct measurements; Fairall et al. 2003) especially for $U_{10}<15 \mathrm{~m} \mathrm{~s}^{-1}$ conditions as in this study, and their influences on the results are considered as negligible.

4) Based on the relationship between $Q_{\mathrm{lw}}$ and $\Delta T$ and the dependency of $\Delta T$ on $\mathrm{SST}_{\text {skin }}$, it is reasonable to assume that there is a positive correlation between the $\mathrm{SST}_{\text {skin }}$ and cool skin amplitude. Meanwhile, it should be noted that there might be multiple other processes that are correlated or coupled to SST and are the true causes behind this dependency.

5) Over the nighttime period, the cool skin does not remain constant. There is a discernible increase in $\Delta T$ amplitude after midnight until dawn (from $\sim-0.20 \mathrm{~K}$ to $-0.37 \mathrm{~K})$. Maximum skin effect is observed at around sunrise.

6) Direct evidence of warm skin is observed in this study. Although not all positive $\Delta T$ values necessarily correspond to real warm skin due to data uncertainty, it is believed that those measured under positive $Q_{\text {net }}$ conditions make physical sense and indicate true warm skin events. Warm skin is more likely to be observed at high latitudes with very humid air, which is warmer than $\mathrm{SST}_{\text {skin }}$.

7) Overall, F96 has performed very well modeling the cool skin effects, although with consistent underestimation of the amplitude under most $U_{10}$ or heat flux conditions by $0.03-0.06 \mathrm{~K}$. However, a few limitations should be noted. For example, as seen in Fig. 6, for $U_{10}>8 \mathrm{~m} \mathrm{~s}^{-1}$ conditions, there is still a steady increasing trend of F96 modeled $\Delta T$ values instead of approaching an asymptote like the observations. More importantly, no warm skin events are allowed 
in F96, which are considered as not "physical," whereas direct warm skin evidence has been observed in this study. This restraint in F96 clearly needs to be modified.

8) The brief validation of the empirical functions, including the new one proposed in this study, indicate that they can capture basic skin-effect features, like the average mean value. However, with its current functional form, it is difficult to extract more details from the modeled skin effect, although being simple to use makes them widely adopted in works such as satellite SST validation.

A better understanding of the ocean cool skin effect can potentially enhance the performance of air-sea interaction, NWP, or climate models. Furthermore, as the skin layer is closely related to wind, hence, wave breaking (Jessup et al. 1997), it can provide a new perspective in wider wave research, such as wave energy dissipation and wave forecast models (e.g., Wick and Jessup 1998).

Acknowledgments. This work was supported by the Australian Research Council Discovery under Project DP170101328. The work of A. V. Babanin was supported by the DISI Australia-China Centre under Grant ACSRF48199. The ISAR and meteorological data were collected and processed by the Australian Marine National Facility and Bureau of Meteorology, and sourced from the Integrated Marine Observing System (IMOS) via IMOS (accessible from http:// thredds.aodn.org.au/thredds/catalog/IMOS/SOOP/SOOPASF/VLMJ_Investigator/meteorological_sst_observations/ YYYY/ISAR-QC/catalog.html, where "YYYY" is "2016," "2017" or "2018"). IMOS is a national collaborative research infrastructure, supported by the Australian Government. We thank Eric Schulz (Bureau of Meteorology) for his advice on treatment of the meteorological data set, and Nicole Morgan (CSIRO) for her advice regarding the ISAR SST error budget. Many thanks also go to Christopher W. Fairall from NOAA for providing the COARE bulk flux algorithm v3.6 codes. The views, opinions, and findings contained in this paper are those of the authors and should not be construed as an official NOAA or U.S. Government position, policy, or decision.

\section{REFERENCES}

Akella, S., R. Todling, and M. Suarez, 2017: Assimilation for skin SST in the NASA GEOS atmospheric data assimilation system. Quart. J. Roy. Meteor. Soc., 143, 1032-1046, https:// doi.org/10.1002/qj.2988.

Alappattu, D. P., Q. Wang, R. Yamaguchi, R. J. Lind, M. Reynolds, and A. J. Christman, 2017: Warm layer and cool skin corrections for bulk water temperature measurements for air-sea interaction studies. J. Geophys. Res. Oceans, 122, 6470-6481, https://doi.org/10.1002/2017JC012688.
Artale, V., D. Iudicone, R. Santoleri, V. Rupolo, S. Marullo, and F. D'Ortenzio, 2002: Role of surface fluxes in ocean general circulation models using satellite sea surface temperature: Validation of and sensitivity to the forcing frequency of the Mediterranean thermohaline circulation. J. Geophys. Res., 107, 3120, https://doi.org/10.1029/2000JC000452.

Beggs, H., N. Morgan, and J. Sisson, 2017: IMOS ship SST for satellite SST validation. 18th Science Team Meeting, Qingdao, China, Group for High Resolution Sea Surface Temperature, 127-134, https://www.ghrsst.org/meetings/18th-internationalghrsst-science-team-meeting-ghrsst-xviii.

Brutsaert, W., 1975: A theory for local evaporation (or heat transfer) from rough and smooth surfaces at ground level. Water Resour. Res., 11, 543-550, https://doi.org/10.1029/WR011i004p00543.

Castro, S. L., G. A. Wick, and W. J. Emery, 2003: Further refinements to models for the bulk-skin sea surface temperature difference. J. Geophys. Res., 108, 3377, https://doi.org/10.1029/2002JC001641.

Clayson, C. A., and A. S. Bogdanoff, 2013: The effect of diurnal sea surface temperature warming on climatological air-sea fluxes. J. Climate, 26, 2546-2556, https://doi.org/10.1175/JCLI-D-12-00062.1.

CSIRO, 2017: Calibration report on instrument SBE38 serial number 0671. CSIRO Oceans and Atmosphere Rep. 5133 T, 2 pp.

Dickey, T., D. Manov, R. Weller, and D. Siegel, 1994: Determination of longwave heat flux at the air-sea interface using measurements from buoy platforms. J. Atmos. Oceanic Technol., 11, 1057-1078, https://doi.org/10.1175/1520-0426(1994)011<1057: DOLHFA $>2.0 . \mathrm{CO} ; 2$.

Donlon, C. J., T. Nightingale, T. Sheasby, J. Turner, I. Robinson, and W. Emergy, 1999: Implications of the oceanic thermal skin temperature deviation at high wind speed. Geophys. Res. Lett., 26, 2505-2508, https://doi.org/10.1029/1999GL900547.

_ , P. Minnett, C. Gentemann, T. Nightingale, I. Barton, B. Ward, and M. Murray, 2002: Toward improved validation of satellite sea surface skin temperature measurements for climate research. J. Climate, 15, 353-369, https://doi.org/ 10.1175/1520-0442(2002)015<0353:TIVOSS > 2.0.CO;2.

_ I. Robinson, W. Wimmer, G. Fisher, M. Reynolds, R. Edwards, and T. Nightingale, 2008: An infrared sea surface temperature autonomous radiometer (ISAR) for deployment aboard volunteer observing ships (VOS). J. Atmos. Oceanic Technol., 25, 93-113, https://doi.org/10.1175/2007JTECHO505.1.

- W. Wimmer, I. Robinson, G. Fisher, M. Ferlet, T. Nightingale, and B. Bras, 2014: A second-generation blackbody system for the calibration and verification of seagoing infrared radiometers. J. Atmos. Oceanic Technol., 31, 1104-1127, https://doi.org/ 10.1175/JTECH-D-13-00151.1.

Fairall, C. W., E. F. Bradley, J. Godfrey, G. Wick, J. B. Edson, and G. Young, 1996a: Cool-skin and warm-layer effects on sea surface temperature. J. Geophys. Res., 101, 1295-1308, https:// doi.org/10.1029/95JC03190.

,,- D. P. Rogers, J. B. Edson, and G. S. Young, 1996b: Bulk parameterization of air-sea fluxes for Tropical OceanGlobal Atmosphere Coupled-Ocean Atmosphere Response Experiment. J. Geophys. Res., 101, 3747-3764, https://doi.org/ 10.1029/95JC03205.

- — - J. Hare, A. Grachev, and J. Edson, 2003: Bulk parameterization of air-sea fluxes: Updates and verification for the COARE algorithm. J. Climate, 16, 571-591, https://doi.org/ 10.1175/1520-0442(2003)016<0571:BPOASF $>2.0$.CO;2.

Gentemann, C. L., C. J. Donlon, A. Stuart-Menteth, and F. J. Wentz, 2003: Diurnal signals in satellite sea surface temperature measurements. Geophys. Res. Lett., 30, 1140, https://doi.org/10.1029/ 2002GL016291. 
Hasse, L., 1971: The sea surface temperature deviation and the heat flow at the sea-air interface. Bound.-Layer Meteor., 1, 368-379, https://doi.org/10.1007/BF02186037.

Hepplewhite, C., 1989: Remote observation of the sea surface and atmosphere: The oceanic skin effect. Int. J. Remote Sens., 10, 801-810, https://doi.org/10.1080/01431168908903920.

Horrocks, L. A., B. Candy, T. J. Nightingale, R. W. Saunders, A. O'Carroll, and A. R. Harris, 2003: Parameterizations of the ocean skin effect and implications for satellite-based measurement of sea-surface temperature. J. Geophys. Res., 108, 3096, https://doi.org/10.1029/2002JC001503.

IMOS, 2018: Sea surface temperature and meteorological data from the RV Investigator-Including reprocessed and qualitycontrolled radiometric sea temperatures. Australian Ocean Data Network, accessed 25 October 2019, http://thredds.aodn.org.au/ thredds/catalog/IMOS/SOOP/SOOP-ASF/VLMJ_Investigator/ meteorological_sst_observations/YYYY/ISAR-QC/catalog.html, where "YYYY" is "2016," "2017" or "2018."

Jessup, A., C. Zappa, M. Loewen, and V. Hesany, 1997: Infrared remote sensing of breaking waves. Nature, $\mathbf{3 8 5}, 52-55$, https:// doi.org/10.1038/385052a0.

Kent, E. C., T. N. Forrester, and P. K. Taylor, 1996: A comparison of oceanic skin effect parameterizations using shipborne radiometer data. J. Geophys. Res., 101, 16 649-16666, https:// doi.org/10.1029/96JC01054.

Liu, W. T., K. B. Katsaros, and J. A. Businger, 1979: Bulk parameterization of air-sea exchanges of heat and water vapor including the molecular constraints at the interface. J. Atmos. Sci., 36, 1722-1735, https://doi.org/10.1175/1520-0469(1979) 036<1722:BPOASE $>2.0 . \mathrm{CO} ; 2$.

Masson, S., P. Terray, G. Madec, J.-J. Luo, T. Yamagata, and K. Takahashi, 2012: Impact of intra-daily SST variability on ENSO characteristics in a coupled model. Climate Dyn., 39, 681-707, https://doi.org/10.1007/s00382-011-1247-2.

Minnett, P. J., 2003: Radiometric measurements of the sea-surface skin temperature: The competing roles of the diurnal thermocline and the cool skin. Int. J. Remote Sens., 24, 5033-5047, https://doi.org/10.1080/0143116031000095880.

- M. Smith, and B. Ward, 2011: Measurements of the oceanic thermal skin effect. Deep-Sea Res. II, 58, 861-868, https:// doi.org/10.1016/j.dsr2.2010.10.024.

Murray, M., M. Allen, C. Merchant, A. Harris, and C. Donlon, 2000: Direct observations of skin-bulk SST variability. Geophys. Res. Lett., 27, 1171-1174, https://doi.org/10.1029/1999GL011133.

Niclòs, R., V. Caselles, E. Valor, C. Coll, and J. Sanchez, 2009: A simple equation for determining sea surface emissivity in the 3-15 $\mu \mathrm{m}$ region. Int. J. Remote Sens., 30, 1603-1619, https:// doi.org/10.1080/01431160802541523.

Paulson, C., and J. Simpson, 1981: The temperature difference across the cool skin of the ocean. J. Geophys. Res., 86, 11044 11 054, https://doi.org/10.1029/JC086iC11p11044.

Robertson, J., and A. Watson, 1992: Thermal skin effect of the surface ocean and its implications for $\mathrm{CO}_{2}$ uptake. Nature, 358, 738-740, https://doi.org/10.1038/358738a0.

Saunders, P. M., 1967: The temperature at the ocean-air interface. J. Atmos. Sci., 24, 269-273, https://doi.org/10.1175/1520-0469(1967) 024<0269:TTATOA $>2.0 . \mathrm{CO} ;$.
Schluessel, P., W. J. Emery, H. Grassl, and T. Mammen, 1990: On the bulk-skin temperature difference and its impact on satellite remote sensing of sea surface temperature.J. Geophys. Res., 95 , 13 341-13356, https://doi.org/10.1029/JC095iC08p13341.

Smith, S. D., 1988: Coefficients for sea surface wind stress, heat flux, and wind profiles as a function of wind speed and temperature. J. Geophys. Res., 93, 15 467-15 472, https://doi.org/10.1029/ JC093iC12p15467.

Soloviev, A. V., and P. Schlüssel, 1994: Parameterization of the cool skin of the ocean and of the air-ocean gas transfer on the basis of modeling surface renewal. J. Phys. Oceanogr., 24, 1339-1346, https://doi.org/10.1175/1520-0485(1994)024<1339: POTCSO $>2.0 . \mathrm{CO} ; 2$.

$\longrightarrow$, and — 1996: Evolution of cool skin and direct air-sea gas transfer coefficient during daytime. Bound.-Layer Meteor., 77, 45-68, https://doi.org/10.1007/BF00121858.

Theocharous, E., and Coauthors, 2019: The 2016 CEOS infrared radiometer comparison: Part II: Laboratory comparison of radiation thermometers. J. Atmos. Oceanic Technol., 36, 1079-1092, https://doi.org/10.1175/JTECH-D-18-0032.1.

Tu, C.-Y., and B.-J. Tsuang, 2005: Cool-skin simulation by a onecolumn ocean model. Geophys. Res. Lett., 32, L22602, https:// doi.org/10.1029/2005GL024252.

Ward, B., 2006: Near-surface ocean temperature. J. Geophys. Res., 111, C02004, https://doi.org/10.1029/2004JC002689.

Wick, G. A., and A. T. Jessup, 1998: Simulation of ocean skin temperature modulation by swell waves. J. Geophys. Res., $\mathbf{1 0 3}$, 3149-3161, https://doi.org/10.1029/97JC03199.

_ , W. J. Emery, L. H. Kantha, and P. Schlüssel, 1996: The behavior of the bulk-Skin sea surface temperature difference under varying wind speed and heat flux. J. Phys. Oceanogr., 26, 1969-1988, https://doi.org/10.1175/1520-0485(1996)026<1969: TBOTBS $>2.0 . \mathrm{CO} ; 2$.

—, J. C. Ohlmann, C. W. Fairall, and A. T. Jessup, 2005: Improved oceanic cool-skin corrections using a refined solar penetration model. J. Phys. Oceanogr., 35, 1986-1996, https:// doi.org/10.1175/JPO2803.1.

Wilson, R. C., S. J. Hook, P. Schneider, and S. G. Schladow, 2013: Skin and bulk temperature difference at Lake Tahoe: A case study on lake skin effect. J. Geophys. Res. Atmos., 118, 10332 10-346, https://doi.org/10.1002/jgrd.50786.

Wimmer, W., and I. S. Robinson, 2016: The ISAR instrument uncertainty model. J. Atmos. Oceanic Technol., 33, 2415-2433, https://doi.org/10.1175/JTECH-D-16-0096.1.

Woodcock, A. H., 1941: Surface cooling and streaming in shallow fresh and salt waters. J. Mar. Res., 4, 153-161.

Wu, J., 1985: On the cool skin of the ocean. Bound.-Layer Meteor., 31, 203-207, https://doi.org/10.1007/BF00121179.

Zeng, X., and A. Beljaars, 2005: A prognostic scheme of sea surface skin temperature for modeling and data assimilation. Geophys. Res. Lett., 32, L14605, https://doi.org/10.1029/2005GL023030.

Zhang, H., A. V. Babanin, Q. Liu, and A. Ignatov, 2019: Cool skin signals observed from Advanced Along-Track Scanning Radiometer (AATSR) and in situ SST measurements. Remote Sens. Environ., 226, 38-50, https://doi.org/10.1016/ j.rse.2019.03.035. 